\title{
ORGANIZAÇÃO INICIAL DO ENSINO PROFISSIONALIZANTE FEMININO EM UBERABA/MG: ECONOMIA RURAL DOMÉSTICA (1953-1962)
}

\author{
Nilce Vieira Campos Ferreira \\ Universidade Federal de Mato Grosso/Campus Cuiabá (UFMT) \\ Wenceslau Gonçalves Neto \\ UNIUBE/UFU
}

\begin{abstract}
RESUMO
Objetivamos registrar e analisar o percurso inicial da Escola de Economia Rural Doméstica de Uberaba, como registro histórico e como memória social específica. Temos como fontes documentais relatórios, iconografia e imprensa local e como fontes orais testemunhos de suas protagonistas. Idealizado como Centro de Treinamento em Economia Doméstica, em agosto de 1953, a instituição foi o primeiro estabelecimento federal de ensino profissionalizante, nível secundário, em Uberaba/MG. Desde sua fundação, recebeu múltiplas denominações: Centro de Treinamento em Economia Rural Doméstica, Escola de Magistério em Economia Rural Doméstica "Licurgo Leite", Escola Agrotécnica Federal de Uberaba, Centro Federal de Educação Tecnológica e, por último, Instituto Federal de educação, Ciência e Tecnologia do Triângulo Mineiro - IFTM/Campus Uberaba. No texto, discutimos medidas legais emitidas pelo Governo Brasileiro para quem a formação profissionalizante, no período delimitado, representava um instrumento para a formação das massas, sendo preciso incluir a formação das mulheres. Apresentamos, dessa forma, uma análise dos modelos de formação feminina e a relação entre a história do hoje IFTM/Campus Uberaba e o ensino profissional agrícola no Estado de Minas Gerais.

Palavras-chave: Educação feminina; Magistério em Economia Rural Doméstica; Memória das instituições escolares; História da Educação.
\end{abstract}

\section{THE INITIAL ORGANIZATION OF THE FEMALEPROFESSIONALIZING TEACHING IN UBERABA/MG: DOMESTIC RURAL ECONOMY}

\begin{abstract}
It is our intention to focus and analyze the initial route of the Rural Domestic School of Uberaba as historical record and as specific social memory. Our historical sources are documentary reports, iconography and the local press as well as the oral sources testimony of the performers. Projected as a training center of domestic economy in August 1953, the institution was the first federal entity of professionalizing teaching, secondary level, in Uberaba/MG. Since its foundation, it received multiple denominations: Center of Domestic Rural Economy, School of Teaching in Domestic Rural Economy "Licurgo Leite", Federal Center of Agro-technical Education of Uberaba and, at the latest, Federal Institute of Education, Science and Technology of Triângulo Mineiro IFTM/Campus Uberaba. In this text, legal procedures issued by the Brazilian government are discussed, to whom professionalizing education, within the proposed span of time, represented an instrument to educate people, necessarily including women education. In summary, we present an analysis of models of female education and its relation with the history of today IFTM/Campus of Uberaba as well as the professional agricultural teaching in the State of Minas Gerais.

Keywords: Female education. Teaching of domestic rural economy. School institutions memory. History of education.
\end{abstract}




\section{Introdução}

A Escola de Economia Rural Doméstica de Uberaba, doravante denominada ESERD, teve sua origem em 1953, sendo gerida e mantida pela União. Destinava-se à formação de mulheres com difusão de conhecimentos que transferissem à vida familiar noções básicas para a vida no lar, melhoria das rotinas básicas de higiene, técnicas de culinária, em suma os fazeres próprios das mulheres, considerados essenciais à educação familiar. A educação feminina marcava-se por um forte sentido moral e ético, exigido para o ingresso e a permanência da moça na escola.

A criação e, posteriormente a consolidação, da ESERD resultou de uma aliança tácita entre a União, a Igreja conservadora e a oligarquia uberabense que estabeleceu uma educação de cunho conservador para as mulheres em consonância com a expectativa de civilização da sociedade pela escolarização, pretendida pelo Governo brasileiro à época. A escola foi encarada como um meio capaz de aprimorar a vida das famílias. Essa melhoria incluiu a escolarização feminina como meio de aprimorar as condições de vida doméstica e da sociedade como ansiavam as elites no comando da Nação.

Uma educação diferenciada para a mulher, na qual as atividades educativas vinculavam-se ao ensino de técnicas adequadas ao trabalho doméstico, com os quais a aprendiza não podia deixar de travar conhecimentos. Na prática pedagógica diária, a formação para o trabalho foi encarada como método corriqueiro. As alunas executavam trabalhos práticos de agulha, corte e confecção de peças de vestuário, cuidados de higiene e com a casa, culinária, tantos quantos possíveis.

\section{Centro de Treinamento em Economia Rural Doméstica}

A ESERD foi fundada em Uberaba/MG, em 1953, por iniciativa de um Padre uberabense, o Padre Agostinho Zago. A instituição escolar era vinculada à Secretaria Agrícola e Veterinária - SEAV, órgão vinculado ao Ministério da Agricultura.

Sua origem se deu como Centro de Treinamento em Economia Rural Doméstica. Destinava-se a ministrar cursos de treinamento para as atividades do lar, difundindo conhecimentos que possibilitassem às mulheres ocupar-se das atividades domésticas, de modo a melhorar hábitos e práticas habituais, contribuindo para a fixação das populações rurais em suas localidades.

Esses Centros vinham sendo implantados pelo ministro da Agricultura, João Cleophas, a partir de 1950. Para Cleophas (1952), as exigências da produção no país impunham incentivar e estimular a formação da população feminina visando assegurar a prosperidade do país, em especial àquelas voltadas para o meio rural, o que incluía a profissionalização das mulheres para o trabalho no lar e nas áreas destinadas à produção. Para atingir esses fins, as orientações do ministério eram integrar ao ensino profissionalizante feminino princípios que permitissem às mulheres os elementos necessários para promover a melhoria das condições no meio rural brasileiro, por intermédio da ação nas famílias, o que deveria conduzir a uma "promoção do social".

A ESERD adotou as recomendações voltadas para o ensino das mulheres, adotando e difundindo propostas que pudessem contribuir para uma administração mais eficiente do lar e das práticas agrícolas desenvolvidas no meio rural. Cabia o uso de práticas de ensino visando o desenvolvimento da produção brasileira, com a implantação de novas técnicas de exploração, o estimulo e incentivo da juventude, no sentido de levá-los a se interessar pelas carreiras de Agronomia e Veterinária para os moços e para as moças a Economia Doméstica. Essas carreiras foram consideradas imprescindíveis para assegurarem a prosperidade do país, na visão do Ministro Cleophas (1952). 
As mulheres deveriam aprender os princípios da atividade agrícola, noções de alimento e nutrição, habitação, mobiliário, equipamento, saúde da família, higiene, puericultura, enfermagem, vestuário, economia familiar, relações familiares e pessoais, visando sua atuação nas comunidades rurais.

No primeiro ano de funcionamento, de modo improvisado, o Centro foi instalado na Rua Major Eustáquio, na região central de Uberaba, em um suntuoso sobrado cedido pelo Padre Agostinho Zago. No primeiro semestre de sua existência formou 74 aprendizas. As disciplinas ministradas incluíam Arte Culinária, Enfermagem, Corte e Costura, Atividades Agrícolas, Trabalhos Manuais.

O Prédio, cedido pelo Padre Zago, ainda hoje se mantém muito bem conservado. Apresenta características condizentes a um majestoso edifício destinado à instrução feminina, com uma estrutura física apreciável para a época, um "palácio", como dito por Faria Filho (2000), a respeito dos grupos escolares em Minas Gerais. O prédio era composto por dois pavimentos, destinados à administração e às salas de aulas teóricas, além de salas, nas quais seriam abrigadas as diversas aulas práticas e os equipamentos a elas necessários. Essas salas constituíam verdadeiras oficinas de aprendizagem de trabalhos manuais.

Naquele momento, Uberaba era uma cidade progressista, marcada pelos ideais de modernidade. Havia se tornado um importante centro comercial a partir da inauguração da Estrada de Ferro Mogiana, em 1889, um acontecimento facilitador da imigração para a cidade e do desenvolvimento da pecuária zebuína que se aprimorou nos anos que se seguiram. Fazendeiros do Triângulo Mineiro, a partir de Uberaba, introduziram o gado zebu no Brasil. Com isso, a cidade passou a ter expressão econômica no país e no exterior, e se fez um grande reduto econômico e francamente ativo. A pujança econômica se refletia na estrutura urbana uberabense e surgiam requintadas construções como o primeiro prédio destinado à escola.

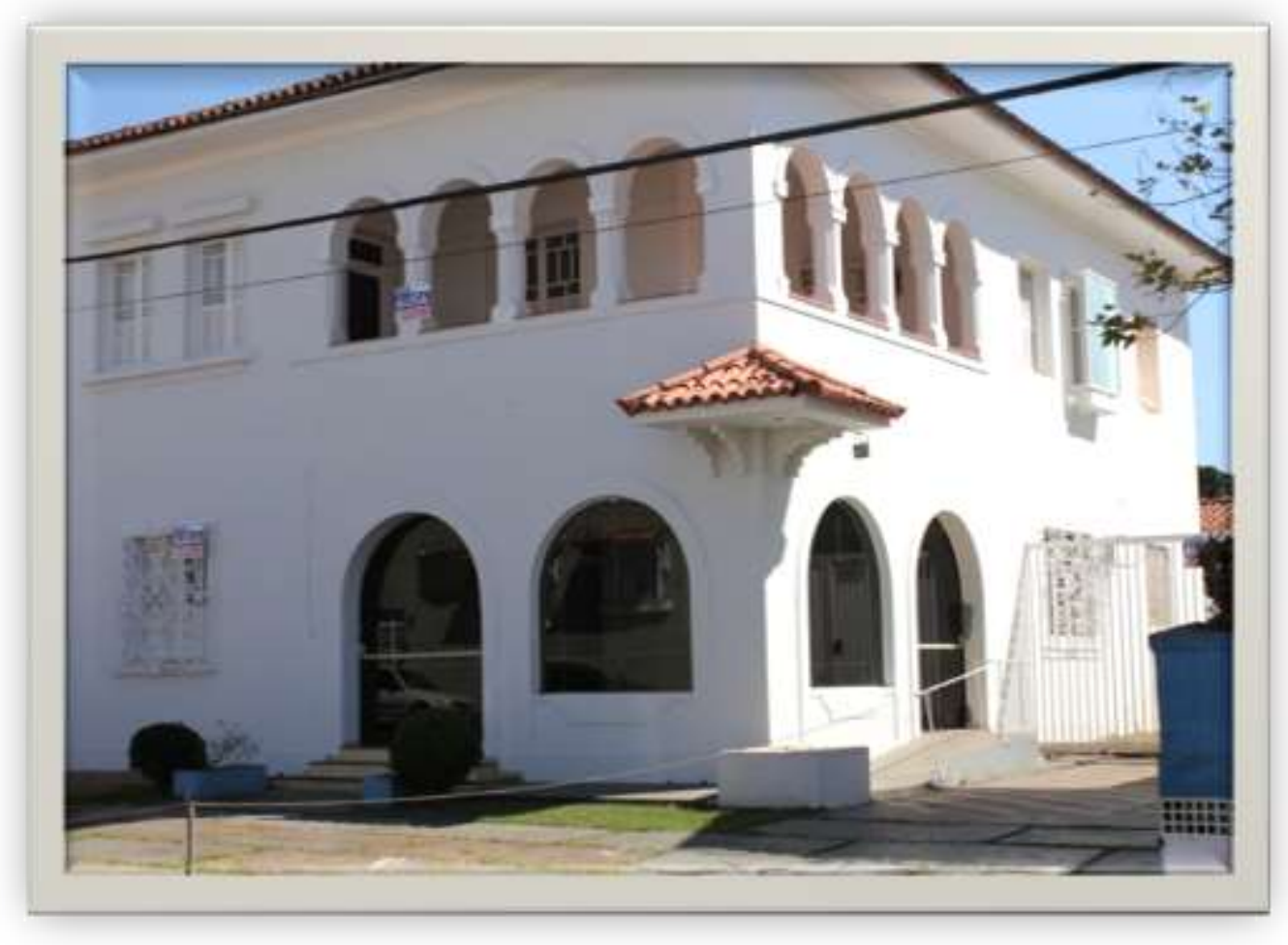

Figura 1: Primeiro prédio onde funcionou a ESERD.

Fonte: FERREIRA (2012, p.134). 
Mendonça (1954), advogado e professor uberabense, em seu discurso por ocasião da inauguração da ESERD, enunciou particularidades da instituição. Para ele a formação oferecida honraria e dignificaria a cultura das mulheres. Era fundamental que a esfera educacional garantisse a estabilidade moral e social uberabenses. A preparação deveria fundamentar-se nas virtudes cristãs, uma formação ufanista que pudesse honrar e dignificar a cultura e a civilização.

A Escola de Economia Doméstica, que se abre em Uberaba, foi a segunda que no Brasil se instala. Compreende um 'Centro de Treinamento', que já começa a funcionar, com numerosas alunas e a Escola de Formação do Magistério de Economia Doméstica Rural, a criar-se no próximo ano. Trata-se, assim, de uma obra que honra, exalta e dignifica a nossa cultura e a nossa civilização. O povo uberabense, que nestes rincões centrais do país, pelo seu bendito idealismo e pela sua incomparável capacidade de esforço e de trabalho, criou uma civilização de que todo o Brasil se ufana, sente neste instante, vibrar todo o seu entusiasmo patriótico, todo o seu infinito amor à grande pátria, agradecendo aos fundadores desta Escola $\mathrm{o}$ benefício magnífico que lhe trouxeram e prometendo-lhes todo o seu apoio, todo o seu amparo, toda a sua dedicação no sentido de dar-se à Escola a expansão e o prestígio que merece e que há de ter (MENDONÇA, 1954, p. 1).

Como notamos, Mendonça (1954) destacou o elevado patriotismo do povo uberabense o que, segundo ele, justificava a existência na cidade de Uberaba de uma escola destinada à formação feminina. Esses indicativos se mostravam coerentes com os ideais vigentes nesse período na sociedade brasileira. $\mathrm{O}$ esforço e o trabalho do povo mineiro e uberabense uniam-se para criar um Estado desenvolvido. Às mulheres também coube um papel diferenciado: elas deveriam adquirir conhecimentos e habilidades que as tornassem capazes de difundir a cultura e a civilização que se queria formar, incluindo o uso e o emprego de recursos naturais para suprir as necessidades dos lares e, por conseguinte, da produção intensiva de bens agrícolas que a nação passou a requerer. Com a aquisição de técnicas e habilidades úteis à vida elas encontrariam fundamentação e conhecimentos práticos necessários para melhorar seus costumes, suas condutas, suas condições de vida. Isso contribuiria para evitar o êxodo para as zonas urbanas que não conseguiam acolher e atender devidamente as necessidades da população que adentrava nesses novos espaços.

O governo brasileiro julgou essencial que o ensino agrícola feminino incluísse a formação em práticas agrícolas e domésticas que evidenciassem novas técnicas produtivas destinadas a tornar o lar rural um local de saúde, felicidade, abundância e, por conseguinte, atrativo. O programa de ensino deveria corresponder a esse ideal com propostas práticas para sanar problemas enfrentados nas áreas de produção agrícola. Deveria buscar, sobretudo, a eficiência da economia doméstica para o bem-estar da Nação. A formação das mulheres na instituição foi então efetivada por esse caminho.

\section{Os cursos de Economia Rural Doméstica}

Em 1954, O Centro de Treinamento foi federalizado. Passou a oferecer o Magistério em Economia Rural Doméstica com a atribuição de formar as mulheres para atuar nos cursos de extensão rural e para ministrar aulas nos cursos técnicos agrícolas. Nesse mesmo ano, passou a ser denominada Escola de Magistério em Economia Rural Doméstica "Licurgo Leite", ministrando apenas dois Cursos: Magistério em Economia Rural Doméstica e o Curso de Treinamento em Economia Rural Doméstica. 
A fixação do homem no campo e o "progresso" das comunidades dependeriam da presença de mulheres esclarecidas que estimulassem e orientassem as atividades e melhoria da qualidade de vida familiar. Dessa forma, o acesso das mulheres à instrução, visando a profissionalização, havia se tornado relevante. O Curso de Economia Doméstica concebia uma formação para as moças adequada à direção de sua casa, para o cuidado com os filhos e para atender às questões de higiene básicas. Propiciava também uma formação condizente com a nova ordem urbana industrial em ampla expansão no Brasil, a partir de 1950, o que levava as donas de casa a valorizar tudo o que pudesse contribuir para uma administração eficiente do lar e que pudesse suavizar a dura rotina dos serviços domésticos diários.

Os estudos de Economia Doméstica destinavam-se assim a ensinar habilidades para as atividades desenvolvidas no lar. As atividades pedagógicas do curso incluíam tópicos como administração da casa, da família e da gestão financeira dos recursos disponíveis. Com a percepção de que as obrigações da casa estendiam-se para além de seus muros, a formação correspondia a uma tentativa de normatização do cotidiano familiar, estabelecendo parâmetros para a educação de uma mulher despreparada para atuar em conformidade com o seu destino "natural" de mãe e esposa. As práticas educativas, dessa forma, foram dirigidas à população feminina, principalmente para qualificar a população rural, numa espécie de missão de apostolado junto à família proletária que se afastava de seus lares no campo com destino à zona urbana, multiplicando os problemas sociais.

As finalidades do Curso de Economia Doméstica, em última instância, visavam preparar mulheres, verdadeiras "profissionais dos assuntos familiares", capazes de atuar e corrigir as anomalias sociais, na perspectiva do serviço social preconizado por orientações da Igreja conservadora católica.

Formar entre mulheres, não de uma classe, mas de todas as classes sociais, uma consciência de comunidade cristã que venha substituir o individualismo liberal egoísta sem cair na socialização inumana e estatal [...] educadores familiares e donas de casa que venham ser no meio em que vivam e trabalham, nos institutos em que ensinam ou nos ambientes sociais em que atuam, como elementos de correção das anomalias sociais, verdadeiros elementos de renovação pessoal e católica (LIMA, 1982, p. 66).

Nesse sentido, considerando a importância da fixação do homem no campo, além de visar o "progresso" dessas comunidades, foi necessário estimular a presença no meio rural de pessoas esclarecidas destinadas a orientar as atividades agrícolas. Contudo, como não havia pessoas com formação adequada para esse tipo de trabalho, dirigentes dos órgãos educacionais brasileiros sugeriram a criação de escolas especializadas, "femininas, autenticamente agrícolas, para preparar moças do interior, capazes de atuar como assistentes sociais rurais, educadoras familiares agrícolas ou auxiliares rurais" (RATTO, 1992, p. 42).

A Economia Doméstica foi encarada na família, no ambiente ou na comunidade como fator de organização, administração e bem estar geral na vida do lar ou no desenvolvimento pessoal do grupo, da comunidade. O curso desenvolvido na ESERD tentou amoldar-se aos princípios que começaram a surgir no Brasil seguindo o modelo americano, consoante os programas de cooperação técnica do Brasil com os Estados Unidos, MEC/USAID.

Esses acordos, estabelecidos entre o Ministério da Educação (MEC) e United States Agency for International Development (USAID) tinham como um dos objetivo promover a reforma do ensino brasileiro. Perpassavam nesses acordos iniciativas do governo para 
principiar e administrar reformas educacionais e sociais, especialmente no campo. $\mathrm{O}$ desenvolvimento econômico deveria ocorrer segundo premissas capitalistas básicas que incluíam uma política "partidária" em relação às classes rurais para integrá-las a uma produção eficiente, provendo mais recursos financeiros à nação. Isso incluía inculcar comportamentos morais e estimular o avanço da produção, o consumo de insumos, produtos e instrumentos industrializados em larga escala adequados a uma família moderna.

Isto é, a modernidade almejada a partir das décadas de 20 e 30 incluía também uma família moderna. Daí a necessidade de uma educação feminina diferenciada de forma a que as mulheres pudessem cumprir com suas obrigações "naturais". A difusão das ideias para a modernização das famílias exigia a criação de um curso que "ensinasse" os comportamentos morais e materiais condizentes com a ordem burguesa (RATTO, 1992, p.40).

Nesse período, os administradores dos órgãos educacionais brasileiros, cujos objetivos políticos e econômicos se estreitavam, tentaram conciliar o modelo político nacional-desenvolvimentista com o modelo econômico de substituição das importações abrangendo a participação do capital estrangeiro. Com esse cenário político e econômico, as atividades de extensão rural se tornaram prioritárias. Em 1953, a Escola de Economia Rural Doméstica de Uberaba/MG incorporou atividades educativas de extensão rural que eram realizadas por meio de campanhas comunitárias junto às famílias, objetivando a transmissão de conhecimentos técnicos. Incluiu também a difusão de modos de planejamento e emprego de recursos naturais de forma mais racional e adequada que pudessem suprir necessidades da família rurais ou urbanas, incluindo hábitos de higiene e cuidados com a saúde. Sendo assim, era indispensável que o curso contivesse noções aprofundadas de "higiene, nutrologia, contabilidade, puericultura, enfermagem" (SERRANO, 1954, p.11).

O desenvolvimento econômico, social e cultural advindo das novas condições de vida oriundas do desenvolvimento industrial aumentavam as exigências de qualificação técnica e intelectual da população brasileira e estimulavam a modernização das condições de produção. Coube especial responsabilidade à formação feminina: a modificação de hábitos e a influência no comportamento das famílias frente a problemas enfrentadas no emprego de práticas agrícolas e domésticas arcaicas e inadequadas à produção que se queria cada vez mais intensiva.

Consoante Ribeiro (2000), nos anos de 1950, cerca de $70 \%$ da população mineira vivia na área rural em condições precárias de saúde, higiene e conforto no lar. A situação de vida da grande massa populacional no país resultava em condições similares e precárias. A deficiência na assistência técnica, educativa, social e financeira prevalecia nos municípios brasileiros. As habitações rurais eram feitas de material rústico, coerentes com hábitos locais e a facilidade de se obter material de baixo custo. As casas de alvenaria eram quase inexistentes. O governo e as organizações econômicas, educativas e sociais, nesse contexto, julgavam serem necessárias ações eminentemente educativas e não apenas políticas, dirigidas às comunidades rurais com a função de educá-las para a utilização de práticas agrícolas mais eficazes.

\footnotetext{
"A situação geral do Estado de Minas Gerais, no final da década de 1940 e durante a primeira metade da década de 1950, guardadas as características de cada região, era representada por problemas básicos de deficiência de saúde, de saneamento, de alimentação e de nutrição, de baixa renda, de baixo índice de produtividade da atividade agropecuária,
} 
de pequena capitalização das unidades de produção e, especialmente, de muito baixa produtividade da mão-de-obra, tanto familiar como ocasional, além da baixa escolaridade da população rural" (RIBEIRO, 2000, p. 64).

A necessidade de novas "práticas educativas" se tornou evidente, especialmente nos anos de 1950 quando trabalhadores rurais começaram um processo de mobilização política organizada de apoio à reforma agrária por meio, por exemplo, das ligas camponesas. Esse fator foi um dos mais relevantes para explicar o redirecionamento da "cooperação" promovida pelos EUA relacionados às atividades educativas e tão imperiosas para a formação escolar da população brasileira (MENDONÇA, 2006).

Com isso, a política brasileira do período, caracterizada pelo populismo, nacionalismo e desenvolvimentismo, vislumbrou nesses movimentos, a necessidade também de uma formação destinada à mulher, uma formação para a dona de casa como uma forma de contrabalancear e garantir a estabilidade social e política notadamente das classes mais desfavorecidas. Associava-se, deste modo, a formação da classe trabalhadora ao Estado como modo de garantia de um relativo "bem estar", isto é, do conforto no lar tão imprescindível ao bom funcionamento da sociedade. A formação destinada ao público feminino deveria ser difundida como uma responsabilidade, um sacerdócio feminino a ser desempenhado como um dever visando o bem-estar das famílias. Não cabia mais uma visão puramente conservadora da educação feminina e o "questionamento de modelos passados desafiava as noções de tradição e autoridade e implicava uma crença de progresso e desenvolvimento constante da humanidade" (SCHWARTZMAN, 2004, p.11).

Para Ratto (1992, p. 13), o modelo de educação para a mulher na Economia Doméstica visava a formação de verdadeiras "tecnocratas da vida cotidiana, altamente qualificadas, dotadas de uma prática de intervenção coerente com a ordem moral, adotando temas de prevenção". Dessa forma, a economista doméstica formada no curso era uma mulher virtuosa, "anjo do lar", "boa doméstica" ou "boa dona-de-casa". Esse era um ideal que se converteria numa aspiração progressivamente assumida pelas mulheres rurais. Esse processo de transferência de conhecimento técnico integrado a normas de produtividade em um lar moderno, cuja função seria consumir, cabia ser gerenciado racionalmente. Esse modelo de educação familiar, com o objeto explícito a produção de especialistas, contudo, só se tornaria viável com o estabelecimento de relações sutis, cordiais com as diversas comunidades que deveriam adotar as propostas promovidas nos cursos, adotando as normas de racionalização e cientifização do lar.

O horizonte cultural e social daquele momento para a educação feminina visava, antes de tudo, ao processo de transferência de conhecimentos técnicos que servissem para auxiliar o marido na lida diária com a produção agrícola. Isso se tornaria viável com o estabelecimento de relações sutis, cordiais, estabelecidos pelas mulheres, economistas domésticas, com as diversas comunidades rurais visando adoção dessas novas técnicas de produção consoantes propostas resultantes dos acordos brasileiros e americanos e para atender à população que crescia rapidamente.

No Brasil, a entrada de capitais, tecnologias e projetos externos era discutida como opção para acelerar o desenvolvimento. Prevalecia um certo consenso entre os grupos da elite na defesa da rápida e extensiva industrialização, muito embora houvesse divisões entre grupos que formavam a burguesia brasileira. Minas Gerais encontrava-se pronta para receber capitais e programas de desenvolvimento em expansão pelo país (RIBEIRO, 2000).

A disposição política em dar destaque a Minas no cenário nacional, a busca de melhorias na qualidade da produção agrícola e a fixação do homem no campo voltaram a 
ênfase desses programas de desenvolvimento para a ação educativa. Essas ações recaíram sobre a necessidade de se educar a família por meio da mulher, pois seria impossível "conceber-se a ideia da pátria sem se admitir a família, o primeiro grupo social, - o mais essencial de todos os elementos que compõem as grandes aglomerações de homens chamadas nações". À mulher, à mãe de família, à boa dona de casa na modéstia de suas tarefas, coube a formação das novas gerações, tornando-a "uma criatura útil à sua pátria e à humanidade" (SERRANO, 1954, p.16-17).

A ESERD imbuiu-se dessa visão de que à mulher competia, portanto, a obrigação de ser a mais bem habilitada possível por que devia à sua família e à sociedade a máxima dedicação em busca de uma organização regular e eficiente da vida familiar. Para atender essas necessidades "na família e no lar doméstico, no decorrer da vida cotidiana, é que poderão e deverão ser perfeitamente executados os preceitos, as regras e as normas [...] frutos da experiência e da razão. A ciência e a técnica doméstica enriquecem-se todos os dias de novos conhecimentos" (SERRANO, 1954, p.12).

Assim as noções aprendidas no estudo da Economia Doméstica serviriam à jovem "no futuro, na vida prática, na resolução de problemas domésticos, da mesma forma que os conhecimentos hauridos na escola pelo estudante de engenharia ou de medicina". Era no ambiente familiar que cabia sua atuação "desde o primeiro dia de vida, continuando depois também no ambiente escolar, que se inicia o trabalho feminino para a formação do homem ou da mulher, daquele elemento útil de que o Brasil e o mundo vão precisar" (SERRANO, 1954, p.14).

Nessa linha, a reforma proposta por Gustavo Capanema como Ministro da Educação e Saúde, a partir do ano de 1942, com publicação das Leis Orgânicas, introduziu também normas para o ensino feminino. A reforma proposta por Capanema compôs a educação feminina diferenciada da masculina. O homem deveria ser preparado para o serviço militar, para os negócios e as lutas. À educação feminina cabia o espaço de organização familiar. Os cursos tinham a finalidade de desenvolver nas moças o gosto pelos trabalhos do lar, preparando verdadeiras mães e perfeitas donas de casa. O escopo da educação era preparar o homem para as ocupações relacionadas à produção e a mulher para o serviço doméstico e o cuidado com marido e os fillhos (SAVIANI; et. al. 2004).

Em 1946, no escopo da Reforma Capanema composta pelas Leis Orgânicas do Ensino Secundário - Decreto-Lei n. ${ }^{\circ}$ 4.244/ 42; do Ensino Industrial - Decreto-Lei n. ${ }^{\circ}$ 4.073/42; Lei Orgânica do Ensino Comercial - Decreto-Lei n. ${ }^{\circ}$ 6.141/43; foi publicado o Decreto-Lei n. ${ }^{\circ}$ 9.613/46, a Lei Orgânica do Ensino Agrícola que regeria o ensino de Economia Rural Doméstica ministrado na ESERD até a Lei de Diretrizes e Bases promulgada em 1961.

A educação feminina foi assumida na ESERD acoplada às transformações ocorridas nesse período e que atribuía papel distinto no cenário da educação feminina conservadora que se desejava para as mulheres. Nada mais útil e imprescindível que uma educação diferenciada para elas, pois "tão complexos se apresentam os problemas da família, que a dona de casa, no seu viver diário, necessita de um conjunto sistematizado de variados conhecimentos científicos, afim de que suas tarefas não sejam desempenhadas empiricamente" (SERRANO, 1954, p.15). Em Uberaba, essa visão a respeito da formação destinada às moças, de sua importância na família era amplamente divulgada.

As moças são a imagem preciosa de nossa mãe quando tinha nossa idade. [...] uma famoso semanário francês dedicado à mulher realizou um espécie de investigação elegante, entre homens ilustres, a fim de apurar quais motivos prendem um homem ao lar [...] 1. O sorriso da esposa. 2. A mesa bem posta e os pratos gostosos. 3 . O conforto que os faz sentir em 
sua própria casa. 4. O acolhimento que a esposa faz a seus amigos, levando-os a fazer boa figura. 5. Os móveis de bom gosto completados por um arranjo de bom gosto. 6. A ordem e certa vaidade feminina. 7. O respeito e a compreensão que a esposa nutre pelo seu trabalho. 8. Os filhos bem educados. 9. O calor do afeto familiar. (MOREIRA, 1953, p. 5)

Com o título "Correio no lar", o Correio Católico, jornal de ampla circulação na época, espalhava uma referência clara ao que era esperado das mulheres: uma conformação às representações socialmente construídas nas relações sociais, o que as levaria a moldar filhos bem-educados, com boa figura, moças com "ordem e certa vaidade feminina". Essa imagem ideal das classes médias deveria se tornar gradualmente uma aspiração das classes trabalhadoras. Mulheres comportadas que confirmassem o ideal de "ordem e progresso", inscrito na bandeira brasileira, em torno do qual se moldavam os programas de ensino na ESERD.

Pode-se inclusive, estabelecer uma ligação com a profissional que o Magistério em Economia Rural Doméstica deveria formar a partir de 1954: uma moça destinada ao magistério rural, orientando as famílias para as melhorias e administração do lar, tornandoo mais agradável, promovendo melhoria nos processos de alimentação, nutrição, saúde, higiene, desenvolvimento humano, vestuário, habitação, além de outras atividades que pudessem contribuir ainda mais para atender as necessidades básicas da família. Em suma, uma figura que refletisse "a imagem preciosa de nossa mãe".

Prevalecia e era largamente divulgada a ideia de que à mulher cabia o papel de guardiã do lar, aquela de quem se esperava ser um bastião moral e social do povo. Mais do que isso, ela deveria ser a ponte de transição entre as gerações, mantendo as concepções de vida, aceitando as tradições, mas também os anseios de futuro e de progresso concernentes à moderna vida que se desejava para a sociedade brasileira.

Antigamente a vida rodava a vinte quilômetros. Hoje ela segue vertiginosa e absorvente. As defesas são outras, os métodos mais rápidos. Os conhecimentos mais técnicos, as exigências mais profundas. A moça tem que saber eletricidade. Tem que ser bombeira, cozinheira, lavadeira e motorista. Tem que ser enfermeira e professora. E tem ainda que ser esposa. Tem que ser mãe [...] Tem que ser amiga. Tudo isso, de forma católica, feminina [...] (NETO AL, 1953, p. 6).

O que se esperava das mulheres, em suma, era a ampliação de suas atividades para além dos muros da casa sem, contudo, ministrar uma profissionalização feminina definida, que não fosse para o magistério ou a assistência social. Isso por que a sociedade conservadora ainda não se preparara para o ingresso da mulher nas diversas atividades industriais que se alastravam no país. Cabia, portanto, à economia doméstica despertar nas mulheres um novo sentido para a vida social e para a consciência de sua missão na família.

$\mathrm{Na}$ sua ligação com a evolução das cidades, para seu horizonte social e cultural deveria prevalecer a ideia de ocupação de um espaço feminino na divisão social e técnica do trabalho, com a perspectiva de ampliar referenciais técnicos para o ensino, para a melhoria da produção agrícola e das atividades domésticas, com a adoção de regras que fossem capazes de colaborar com a implantação e o desenvolvimento da ordem econômica e industrial da sociedade brasileira capitalista em expansão. 


\section{Medidas legais e suas implicações}

Com o advento da Lei Orgânica do Ensino Agrícola, Decreto Lei no 9.613, de 20 de agosto de 1946, a SEAV viu-se com a tarefa de criar cursos de formação com destaque para os conhecimentos práticos destinados à população rural, difundindo técnicas e habilidades agrícolas essenciais à subsistência das comunidades. Os cursos de Economia Doméstica surgiram compreendendo a formação docente ou administrativa ligada ao ensino agrícola.

Art. $9^{\circ} \mathrm{O}$ segundo ciclo do ensino agrícola compreenderá duas modalidades de cursos de formação; os cursos agrícolas técnicos e os cursos agrícolas pedagógicos.

$[\ldots]$

$\S 2^{\circ}$ Os cursos agrícolas pedagógicos destinam-se à formação de pessoal docente para o ensino de disciplinas peculiares ao ensino agrícola ou de pessoal administrativo do ensino agrícola. São os seguintes, o primeiro com a duração de dois anos e os outros com a duração de um ano:

1. Curso de Magistério de Economia Rural Doméstica.

2. Curso de Didática de Ensino Agrícola.

3. Curso de Administração de Ensino Agrícola (BRASIL, 1946).

A partir desse Decreto, a SEAV iniciou nas escolas de Economia Doméstica dois cursos de ensino destinado às mulheres: a) Magistério de Economia Rural Doméstica, nível secundário; b) Cursos de Extensão de Economia Rural Doméstica. O currículo do curso de Magistério de Economia Rural Doméstica era de apenas dois anos. Os Cursos de Extensão variavam de seis meses a um ano, sendo denominados cursos rápidos ou cursos de treinamento de acordo com sua duração.

A Economia Doméstica era compreendida como "trabalhos manuais", como ensino de prendas domésticas para possibilitar à moça rápida absorção e aprimoramento de técnicas para o trabalho no lar. Colocado no currículo secundário pela Reforma Capanema, esse ensino profissionalizante era visto como um programa com bases científicas de aplicação eminentemente prática aplicado nas escolas profissionais com o intuito da formação das "futuras donas-de-casa". A Economia Doméstica passou a ser entendida com essas bases porque propunha conhecimento de nutrição racional, higiene da família e da casa, noções de administração e finanças do lar. Muito embora utilizasse princípios básicos da Economia Geral, tais como a divisão do trabalho e do consumo coletivo, acabaram por se voltar apenas para as melhorias domésticas. Incluía ideias artísticas, estéticas, como o gosto no decorar e aparelhar a casa e também a apresentação cuidadosa das mais simples tarefas da vida cotidiana.

Os cursos ministrados na ESERD propendiam a uma formação com o intento de levar as aprendizas à aquisição de conhecimentos que as possibilitassem modificar comportamentos rotineiros por meio de uma educação que transferisse para a vida familiar os saberes assimilados. Outra função era a de formá-las como orientadoras para os Cursos de Extensão Rural e para o ensino agrícola. O curso de Magistério em Economia Rural Doméstica visava especificamente a formação de pessoal docente para o ensino de disciplinas peculiares ao ensino agrícola ou para a atuação como técnico administrativo das escolas destinadas ao ensino agrícola.

Como o Brasil enfrentava momentos de crise, principalmente política, a criação desses cursos possibilitava a adoção de uma postura promissora de desenvolvimento. 
Acreditava-se que atuar no campo, por meio da educação, promoveria novas ações sociais, políticas e econômicas com o intuito de atender aos anseios da população. O ensino da Economia Doméstica também poderia promover mudanças sociais, uma vez que as mulheres assumiam novos papeis que tiveram lugar com o advento da revolução industrial. Isto é, como campo de conhecimento referente às funções familiares, o curso poderia prover eficácia científica nas tarefas cotidianas da casa, permitindo a elas estruturar melhor a vida familiar.

Era exigência para a matrícula no Curso de Magistério de Economia Rural Doméstica, o certificado de conclusão do primeiro ciclo de ensino de grau médio. No ato da matrícula deveriam ser apresentadas 03 fotografias, Certidão de nascimento, Atestados de saúde e vacina; Requerimento para matrícula, Atestado de bons antecedentes fornecidos pelo delegado da cidade, certificado de conclusão do primeiro ciclo de ensino de grau médio. Para os cursos de treinamento eram solicitados apenas o certificado conclusão do primeiro ciclo.

O programa para o Curso de Magistério em Economia Rural Doméstica, com duração de apenas dois anos, abrangia as seguintes disciplinas para a $1^{\mathrm{a}}$ e a $2^{\mathrm{a}}$ séries: Corte e Costura, Português, Matemática, Ciências Físicas e Naturais, Dietética e Arte Culinária, Indústrias Rurais Caseiras, Confecção de Adornos e Utensílios Domésticos, Administração e Arranjos do Lar, Atividades Agrícolas, Desenho Aplicado, Higiene e Enfermagem, Noções de Puericultura, Sociologia Rural, Psicologia Educacional, Metodologia, Administração Escolar, Recreação e Jogos educativos.

Cabe ressaltar que até 1961 a SEAV manteve apenas cinco Escolas de Magistério de Economia Rural Doméstica, ensino profissionalizante técnico de nível secundário, em funcionamento: a) Escola de Magistério de Economia Rural Doméstica, Itaguaí/RJ; b) Escola de Magistério de Economia Rural Doméstica "Licurgo Leite" em Uberaba/MG; c) Escola de Magistério de Economia Rural Doméstica em Sousa/PB; d) Escola de Magistério de Economia Rural Doméstica da Escola Agrotécnica "Visconde da Graça", Pelotas/RS; e) Escola de Magistério de Economia Rural Doméstica Rural de Pernambuco. Todas seguindo as mesmas normas propostas pela SEAV. Com a LDB de 1961, essas escolas passaram a oferecer apenas os cursos ginasiais e colegiais disponibilizando a formação agrícola ou em Economia Doméstica.

Apesar de o ensino de Economia Rural Doméstica se constituir uma das atribuições da SEAV, os estabelecimentos que ofereciam essa modalidade de ensino viveram uma série de deficiências, não só de recursos materiais, mas igualmente com a falta de pessoal devidamente habilitado e com recursos quase sempre insuficientes. Isso decorria do crescente aumento do custo de vida que restringia as atividades das instituições existentes, ao progressivo ingresso das mulheres nesse nível de ensino e ao consequente aumento de demanda pelo número de vagas, sem que a capacidade de atendê-las se fizesse coetânea.

Para melhorar o acompanhamento e reorientação do ensino, em 1955, foi criado pelo Ofício SEAV no 54, de 11/01/1955, o Setor de Administração dos Cursos de Economia Rural Doméstica - SAD, com principal atribuição de zelar pelo funcionamento, inspeção, orientação dos cursos e emprego dos recursos indispensáveis ao seu desenvolvimento. Para isso o SAD compôs normas específicas condizentes com os objetivos do curso de Economia Rural Doméstica a ser ministrado à mulher rural que se ocupasse das lides domésticas. Essas normas procuravam atender às necessidades e possibilidades do meio, visando ao bem estar do elemento feminino, à natureza de sua personalidade e ao papel que deveria exercitar na vida do lar (SILVA, 1961, p. 31).

Art. 52. No ensino agrícola feminino serão observadas as seguintes prescrições especiais: 
1. É recomendável que os cursos do ensino agrícola para mulheres sejam dados em estabelecimentos de ensino de exclusiva frequência feminina.

2. As mulheres não se permitirá, nos estabelecimentos do ensino agrícola, trabalho que, sob o ponto de vista de saúde, não lhes seja adequado.

3. Na execução dos programas, em todos os cursos, ter-se-á em mira a natureza da personalidade feminina e o papel da mulher na vida do lar.

4. Nos dois cursos de formação do primeiro ciclo, incluir-se-á o ensino de economia rural doméstica.

5. Além dos cursos de continuação para mulheres que trabalhem na agricultura e destinados a dar-lhes sumário ensino de um ofício agrícola, ministrarão os estabelecimentos de ensino agrícola a mulheres que trabalharem nas lides do lar, cursos de continuação de economia rural doméstica para ensino rápido e prático dos comuns misteres da vida doméstica rural (BRASIL, 1946).

Como se vê, permanecia a ideia de diferenciação na educação dos sexos. Na esfera educacional prevalecia ainda a ideia católica conservadora, com o suposto de uma educação para as tarefas domésticas para as mulheres, de trabalhos condizentes com sua "natureza feminina", de uma formação inferior à do homem e nunca uma educação junto a ele.

Somente a partir de 1961, essa realidade começou a ser alterada nos cursos profissionalizantes femininos. Wenceslau Gonçalves Neto (1997) destacou que a partir de 1960, o modelo brasileiro de desenvolvimento baseado na produção industrial substitutiva de importações esgotou-se, acentuando sua dependência do mercado exterior. $\mathrm{O}$ crescimento da demanda por matérias-primas e outros insumos industriais não produzidos no Brasil aumentou consideravelmente e o país procurou novas políticas de crescimento econômico. Com isso, iniciou-se um período de crises econômicas e institucionais que provocaram o colapso do pacto populista e do movimento de substituição de importações.

Com o avanço no desenvolvimento industrial brasileiro, a preparação técnica a ser proporcionada à mulher passou a visar, ao contrário de antes, integrá-la ao serviço nas indústrias o que contribuiria decisivamente para evitar o declínio das famílias e, por conseguinte da sociedade. Tudo isso deveria ser considerado em prol de uma campanha empreendida no sentido de formar técnicos especializados em número cada vez maior, indispensáveis ao desenvolvimento do país.

O Curso de Magistério em Economia Rural Doméstica na instituição funcionou durante o período de 1954 a 1962, ano no qual se formou a última turma. Destinou-se à formação de licenciadas em Economia Rural Doméstica, sem qualquer articulação com cursos de nível superior. As licenciadas poderiam lecionar disciplinas comuns ao curso nas escolas de ensino agrícola ou ali atuar como técnicas administrativas.

\section{Algumas considerações}

Mapear a trajetória da escola de Economia Rural Doméstica de Uberaba contribuiu para o registro da memória escolar e do ensino profissionalizante brasileiro, em específico, memória da formação educacional feminina. As discussões foram eriçadas a partir de uma perspectiva histórica considerando os cursos profissionalizantes agrícolas, descrevendo parte do percurso da formação técnica destinada às mulheres.

Articulada ao texto emergiu uma discussão de medidas legais, nas quais a formação em Economia Rural Doméstica representava uma forma de conservadorismo das 
notabilidades femininas: a preparação das mulheres para o desempenho de ofícios domésticos e sociais. No caso da escola em estudo, para a atuação na melhoria de práticas domésticas e na difusão de técnicas agrícolas destinadas às comunidades localizadas nas áreas rurais mineiras.

Nessa visão, a formação em Economia Doméstica, visava antes de tudo, satisfazer à demanda de cursos de formação para as mulheres, como a sociedade vinhas exigindo, mas um ensino voltado para a conformação feminina, permitindo ao Estado uma relativa garantia de estabilidade social. Com essa intervenção, o Governo esperava atuar na vida privada das famílias, assegurando melhor reprodução da força de trabalho, definindo novas personalidades sociais. Além disso, cabia possibilitar, às classes não possuidoras, uma educação destinada às mulheres para as prendas do lar e rápida absorção das moças nos trabalhos domésticos nas casas da oligarquia dirigente ou em outros trabalhos similares na indústria ou no comércio. Ou seja, por meio da educação destinada às mulheres, ao configurar o ensino doméstico formal, o governo poderia inculcar comportamentos para as pessoas e classes menos favorecidas, buscando a preservação e o bom funcionamento da sociedade.

Para isso, na ESERD, as moças recebiam aulas e treinamento de aprendizados ligados à vida doméstica e familiar, além de orientações para práticas rurais e agrícolas. $\mathrm{O}$ ensino valorizava uma estrutura social que tinha a família como base nuclear. Nessa perspectiva, os homens assumiriam o papel de provedores, cultivando a terra e zelando pelo bom funcionamento da unidade rural e as mulheres se manteriam voltadas às questões da casa e à educação dos filhos. Aliado a isso, ela também deveria contribuir para despertar mudanças necessárias ao contexto desenvolvimentista, ajudando a promover alterações a partir do conhecimento, do uso e da disseminação de técnicas essenciais à vida diária relacionada às atividades domésticas e agrícolas, consideradas tão necessárias ao desenvolvimento do estado mineiro.

\section{Referências}

BRASIL. Decreto-Lei n. ${ }^{\circ}$ 9.613/46. $<$ http://www.jusbrasil.com.br/legislacao/126500/leiorganica-do-ensino-agricola-decreto-lei-9613-46>. Acesso em 01/11/2011.

CLEOPHAS, João. Relatório das Atividades do Ministério da Agricultura em 1952. Rio de Janeiro: Serviço de Informação Agrícola, 1952.

MOREIRA, Mercês Maria. Depoimento masculino. Correio Católico, Uberaba, p. 5, 29 ago. 1953.

NETO AL. Quem pensa não casa. Correio Católico, Uberaba, p. 6, 24 out. 1953.

FARIA FILHO, Luciano Mendes de. Dos pardieiros aos palácios: cultura escolar e urbana em Belo Horizonte na Primeira República. Passo Fundo, RS: UPF. 2000.

FERREIRA, Nilce Vieira Campos. Escola de Economia Rural Doméstica: Ensino Secundário profissionalizante no Triângulo Mineiro (1953-1997). Tese (Pós-graduação Stricto Sensu) - Universidade Federal de Uberlândia, Uberlândia, 2012.

GONÇALVES NETO, Wenceslau. Estado e agricultura no Brasil. São Paulo: Hucitec, 1997. 
LIMA, Arlete Alves. Serviço Social no Brasil: a ideologia de uma década. São Paulo: Cortez, 1982.

MENDONÇA, José. Discurso pronunciado em 03/05/1954, na inauguração da Escola de Economia Doméstica, em Uberaba (MG). Disponível em <http://www.josemendonca.com.br/discurso_ED_03051954.php>. Acesso em 03/03/2012.

MENDONCA, Sonia Regina de. The two dichotomies of agricultural education in Brazil (1930-1960). Estudos sociais agrícolas, Rio de Janeiro, v. 2, Selected Edition 2006. Disponível em <http://socialsciences.scielo.org/scielo.php?script=sci_arttext\&pid=S141305802006000200002\&lng=en\&nrm=iso>. Acesso em 06 set. 2012.

RATTO, Izabel Maria Ribeiro. A visão de família nos cursos de Economia Doméstica. Dissertação de Mestrado, UFRRJ/CPDA, abril de 1992.

RIBEIRO, José Paulo. A saga da extensão rural em Minas Gerais. São Paulo: Annablume, 2000.

SAVIANI, Dermeval; et al. O legado educacional do século XX. Campinas: Autores associados, 2004.

SCHWARTZMAN, Simon. Pobreza, exclusão social e modernidade: uma introdução ao mundo contemporâneo. São Paulo: Augurium, 2004.

SERRANO, Isabel de Almeida. Noções de Economia Doméstica. São Paulo: Nacional, 1954.

SILVA, Noemi Correia. Economia Rural Doméstica: uma realidade na SEAV. In: Encontro de Economia Doméstica. Rio, 22 a 28 de julho de 1960, Série Documenta n. 13. Rio de Janeiro: Ministério da Agricultura, 1961.

Recebido em julho-12

Aprovado em fevereiro-13 